restriction on the disclosure of information; and his speech indicated both full appreciation of the diff. culty encountered in drafting the Bill so as to obtain the essential security without impeding scientific research, and the intention of the Government to work the restrictive clauses sensibly. Mr. Attlee said that the Government had decided to define in the Bill the information which could not be communicated regarding atomic energy, and provide for excluding information about plant in use for purposes other than atomic energy if the connexion with atomic energy was not disclosed. At the committee stage, Mr. Woodburn, joint Parliamentary Secretary to the Ministry of Supply, moved a new sub-section providing that the Minister should not withhold eonsent to the communication of information relating to plant in general use for other purposes if he was satisfied that such information did noti endanger national security, and in moving this amendment $\mathrm{Mr}$. Woodburn indicated that within this strict limitation the Minister bound himself to exclude all such matters as plant for scientific research or educational work.

Mr. Wilmot, speaking on the second reading, said that the drafting of Clause 11 was the best compromise they could make, and reiterated in committee that he could not improve on the definition of his attitude in the sub-section moved by Mr. Woodburn. $\mathrm{He}$ was prepared to free the ordinary laboratory tools of the nuclear physicists by excluding them from the terms of the order under Clause 10, and he undertook as soon as the Bill became law to confer with physicists and other men of science affected with the view of making an order excluding those tools from the categories of plant about which communication was prohibited. Pointing out that the insertion of the words "to his knowledge" brought the words into accord with the Official Secrets Act, Mr. Wilmot emphasized that the clause gave complete freedom for the whole field unless it, was associated with atomic energy plant or proposed plant. Basie scien. tific information was excluded, and while the clause could not be made more restrictive by the Minister, he could gradually loosen the restrictions, and Mr. Wilmot anticipated that there would be more and more exemptions and wider and wider fields outside the clause as it became possible to define more exactly the actual limits of security requirements. Even more than the words of the Primo Minister and the Minister of Supply, the whole spirit of the Government's attitude should be profoundty reassuring to the scientific world. The necessity of securing the utmost freedom for the exchange of scientific knowledge was clearly acknowledged, and also the fact that scientific progress is conditioned by the free flow and interchange of scientific opinion; and when Mr. Richard Law said that whether the Bill was effective for its purpose would depend less on what was in it than on the judgment, energy and good sense with which it was administered, Mr. Wilmot was quick to agree and to assüre the House as to the spirit in which the Government intends to use its powers under the Bill.

36

Mathematics at the Queen's University, Belfast :

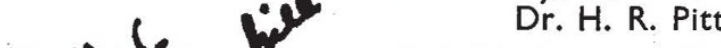
Dr. A R. Rттр who was elected last year at the age of thrty of the chair of mathematics at the Ques. Univessity of Belfast, is recognized as a leader among the younger analysts. He went to
Cambridge as a scholar of Peterhouse in 1932. After taking his degree in 1935, he started research on Tauberian theorems under the direction of Prof. G. H. Hardy. Dissertations in which this was the central theme gained him a bye-fellowship at Peterhouse in 1936 and a Smith's Prize in 1937. Pitt's work was based on ideas introduced into analyses by Norbert Wiener, and the award in 1937 of the Joseph Hodges Choate Memorial Fellowship at Harvard enabled him to continue his studies under the direct influence of Wiener. This period was fruitful, and Pitt wrote further papers independently and in collaboration with Wiener and with Halperin, another member of Wiener's school. On his return from the United States, he became a lecturer at the University of Aberdeen, until his services were claimed during the War by the Air Ministry. H/b \section{Application of Radio and Radar to Astronomical} Research

THe Qpenillonal Research Group of the Ministry of Suppl had recently done much to demonstrate the potehtialities of radio and radar equipments as ins runents for astronomical research. An antiaircaft equipment operating on wave-lengths around 5 ntres has proved to be particularly suitable for three different investigations of astronomical interest. The receiver has been adapted for automatic recording of the intensity of the sunspot radio noise emissions discovered by Sir Edward Appleton and J. S. Hey (Nature, 156, 534 (1945); 157, 47 (1946)). The receiver has also been employed for detailed mapping of the distribution and characteristics of radio noise emissions of cosmic origin at 5 metres wave-length by J. S. Hey, S. J. Parsons and J. W. Phillips (Nature, $157,296(1946) ; 158,234$ (1946)). The complete radar equipment, with modifications originally introduced in 1944 for tracking V2, has been used by J. S. Hey and G. S. Stewart (Nature, 158, 481 (1946)) for radar observation of the streaks or trains of ionization caused by the passage of meteors through the upper atmosphere. In addition to the intrinsic interest which arises in the occurrence of the above phenomena at such wave-lengths, radio and radar methods, although they cannot attain the directional precision of optical instruments, have the. advantage that observations can be made in all weathers and at all times of the day.

\section{War-time Training of Radio Personnel}

The Radio Seclon of the Institution of Electrical Engineers heldjus first meeting for the-current session on Octobpr. when Prof. Willis Jackson delivered his inargulal address as chairman of the Section. The first pat of this address dealt with "The War-time Edudotion and Training of Radio Personnel" and descfibed the war effort, hitherto unrecorded, of the universities and technical colleges of Britain in educating and training a large number of persons for specialized radio work in the Services, Government establishments and in industry. In all, some five thousand men passed through university courses, of six terms duration, affording a substantial instruction in radio as a preliminary to their recruitment, training and employment as radio officers in the Forces, as scientific or technical officers in Service radio establishments or in the radio industry; while upwards of 70,000, including a small proportion of girls, completed courses of four months duration in technical colleges leading to their employment as 'radio' or 'wireless' mechanies, the former being con- 